\title{
Evaluation of Internal Nasal Valve Using Computed Tomography After Le Fort I Osteotomy: A Cross- Sectional Study from a Tertiary Center
}

\author{
๑ Emrah Dilaver, ๑ Kivanc Berke Ak, ๑ Muazzez Suzen, • Gokhan Altin*, • Sina Uckan \\ Istanbul Medipol University Faculty of Dentistry, Department of Oral and Maxillofacial Surgery, Istanbul, Turkey \\ *Istanbul Medipol University, Faculty of Medicine, Department of Otolaryngology, Istanbul, Turkey
}

Abstract

\begin{abstract}
Aim: Internal nasal valve, which has been the most resistant region of the nasal airway, is affected by Le Fort I osteotomy. This study aimed to investigate the changes in the internal nasal valve (INV) after Le Fort I osteotomy.

Methods: A retrospective computed tomography $(\mathrm{CT})$ data of thirty-two patients who underwent Le Fort I surgery alone or combined with mandibular surgery from 2018 to 2020 were evaluated. INV area, INV angle, external nasal valve area, and interalar width were measured at preoperative (T1) and postoperative period (T2) on CT images.

Results: CT assessment showed that the INV area was increased for both the right and left side $(p 1=0.005, p 2=0.007)$. Right and left INV angle was increased from $16.15 \pm 3.24^{\circ}$ to $19.63 \pm 5.21^{\circ}$ and from $15.93 \pm 3.26^{\circ}$ to $19.17 \pm 4.43^{\circ}$ respectively $(p 1=0.000, p 2=0.007)$. Interalar width was increased at the postoperative period $(p=0.000)$. Also, the correlation between interalar width and INV area was found borderline significant $(p=0.051, r=0.814)$. Right and left external nasal valve areas were increased after surgery $(p 1=0.000$, p2=0.003).
\end{abstract}

Conclusion: Maxillary surgery and surgical procedures affecting interalar width have an impact on the internal nasal valve.

Keywords: Internal nasal valve, airway resistance, dentofacial deformities, tomography, orthognathic surgery

\section{Introduction}

Airflow resistance during breathing is essential for good pulmonary function (1). The nasal airway resistance constitutes about $50 \%$ of total airway resistance, and the most resistant region of the nasal airway is the internal nasal valve (INV) (2). The narrowest part of the nasal passage, INV, where the turbulence of inspiratory and expiratory flow occurs, is the most critical valve that adjusts the airflow (3). The INV is located at the inferior aspect of the upper lateral cartilage and is surrounded by inferior nasal concha and nasal septum (4). Small changes in the INV can significantly impact airflow resistance, affecting nasal function (5). A previous study stated that the average INV area was less than $0.38 \mathrm{~cm}^{2}$ in obstructed airway patients, while the normal INV was measured as $0.51 \mathrm{~cm}^{2}$ (4). Theodore (6) stated it should be between approximately 40 to $60 \mathrm{~mm}^{2}$. Many studies reported an increase in the INV area correlated with a higher patient satisfaction level for breathing $(7,8)$. The factors affecting the nasal valve area are septal deviation, turbinate hypertrophy, skeletal irregularities, iatrogenic collapse, and mucosal hypertrophy (4). One possible factor affecting the INV is Le Fort I osteotomy, a commonly used method for treating dentofacial deformities in adult patients. As a result of maxillary impaction or advancement, nasal airway resistance can be decreased because enlargement of interalar width affects an increase in nasal valve angle (9).

Most studies assessing the nasal airway resistance following maxillary surgery used anterior rhinomanometry (AR) and acoustic rhinometry. However, the efficiency of these devices in the determination of nasal airway resistance and clinical applicability is limited $(8,10,11)$. Computed tomography (CT) is an objective imaging

Address for Correspondence: Emrah Dilaver, Istanbul Medipol University Faculty of Dentistry,

Department of Oral and Maxillofacial Surgery, Istanbul, Turkey

E-mail: emrahdilaver@gmail.com ORCID: orcid.org/0000-0003-4522-1424

Received: 05.05.2021 Accepted: 23.05.2021

'Copyright 2021 by The Medical Bulletin of istanbul Haseki Training and Research Hospital The Medical Bulletin of Haseki published by Galenos Yayınevi. 
technique in evaluating the INV anatomy. In previous studies, CT findings were highly correlated with patients' complaints and clinical examination findings $(11,12)$. To the best of our knowledge, there has been no study examining changes in internal nasal valves using CT following Le Fort I surgery.

The purpose of this study was to explore changes in the INV area, INV angle and investigate associated parameters with the internal nasal valve, such as interalar width and external nasal valves.

\section{Methods}

\section{Study Design}

Ethics committee approval of this retrospective study was obtained from Istanbul Medipol University Ethics Committee (date: 07/01/2021, no: E-10840098-772.02947). A written consent form was collected from each patient. The sample consisted of thirty-two patients who underwent Le Fort I surgery between 2018 and 2020 in the Oral and Maxillofacial Department of Istanbul Medipol University Dentistry faculty. Patients who had pre and postoperative CT (at least six months) were included in this study. The exclusion criteria were as follows: 1Patients who underwent multi-piece Le Fort I osteotomy, 2- Patients with congenital deformities such as cleft lip and palate, 3- Patients with a previous history of surgery in internal and external nose 4- Patients with incomplete pre and postoperative $\mathrm{CT}$ records.

\section{Measurement Methodology}

On the cephalometric tracing module of NemoFab software (Nemotec S.L., Madrid, Spain), the horizontal distance between A point to Nasion Perpendicular was defined as maxillary advancement amount, the vertical distance between A point to Nasion point defined as anterior impaction amount. The rotation amount of maxilla was recorded by 3D surgical simulations on preoperative CT using NemoFab software. Positive values were given for maxillary advancement, superior movement of the maxilla, and left maxillary rotation. Negative values were given for maxillary setback, inferior movement of the maxilla, and right maxillary rotation.

A multi-slice CT device (MSCT, Philips Brilliance ICT 256; Philips Medical Systems, Eindhoven, The Netherlands) (scan setting $120 \mathrm{kV}, 150 \mathrm{mAs}$ ) was used slice thickness 0.75 to $1.25 \mathrm{~mm}$. For measurements on internal nasal valves, pre and postoperative coronal CT scans were reformatted perpendicular to the anterior aspect of the estimated acoustic axis described by the previous study (Figure 1a) (13). They showed a correlation between acoustic rhinometry (AS) findings and coronal CT slice obtained at the acoustic axis. Slice of CT was obtained by RadiAnt DICOM 2.2.9 Viewer (Medixant, PoznanPoland). Interalar width and external nasal valve area were measured on a surface model obtained from CT.

\section{Following measurements were taken:}

Right and left INV angle ( $r$-INV angle-IINV angle): Defined as the angle between two lines passing from medial and lateral nasal airway lumen margins (Figure 1b).

Right and left INV area (r-INV area-IINV area): Defined as the inner surface area of soft tissues of the nasal airway (Figure 1c).

Right and left external nasal valve area ( $r$-ENV areaI-ENV area): Inner surface area of right and left nostrils (Figure 2).
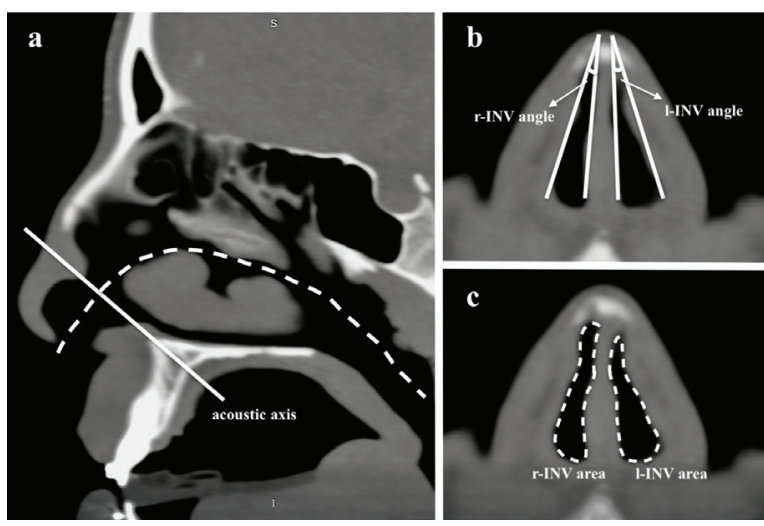

Figure 1. Measurements of internal nasal valve area at the acoustic axis. a: acoustic axis; b: right and left internal nasal valve angle ( $r$-INV and IINV angle); c: right and left internal nasal valve area ( $r$-INV and I-INV area)

INV: Internal nasal valve

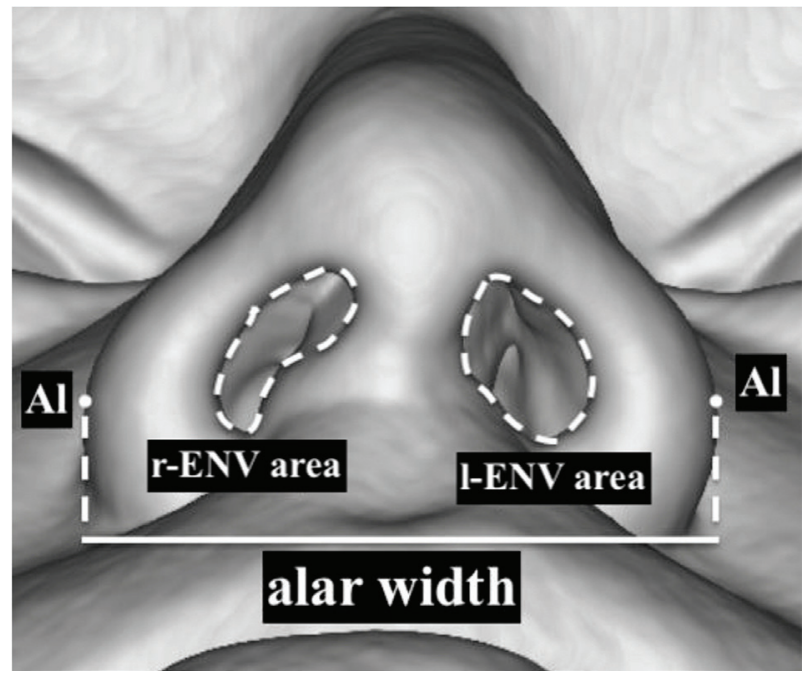

Figure 2. Measurements of the external nasal valve and interalar width.

r-ENV area: right external nasal valve area, I-ENV area: left external nasal valve area, Al: most lateral point of alar curvature r-ENV: R-external nasal valve 
Interalar width: Distance between the right and left alar wing's farthest points (Figure 2).

\section{Surgical Technique}

Under general anesthesia, local anesthetic solution (2\% lidocaine and epinephrine 1:1000,000 IU) was applied to the maxillary vestibular sulcus. Horizontal incision at vestibular sulcus was performed at the level of the mucogingival junction from the first premolar to the contralateral first molar. After incision, the anterior nasal spine, pyriform aperture, and lateral surface of the maxillary sinus were exposed. Le Fort I osteotomy was performed. Maxilla was fixed in the new position by four $2.0 \mathrm{~mm}$ mini plates (KLS Martin, Tuttlingen, Germany) and screws. Alar base cinch suture passing from the right and left alar base to a drilled hole on the anterior nasal spine was performed with 2.0 Nylon. This suture was tightened up to pre-measured alar base width. The wound edges were sutured with a 4.0 vicryl suture (Ethicon; Johnson and Johnson Medical, Norderstedt, Germany).

\section{Statistical Analysis}

The paired samples t-test was performed to compare pre and postoperative measurements using Statistical Package for the Social Sciences (SPSS for Windows, version 18.0, SPSS Inc., Chicago, USA). Pearson's correlation test was used for correlations. $\mathrm{P}<0.05$ was considered significant.

\section{Results}

This retrospective study included 32 patients (21

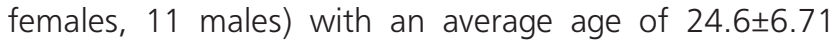
years. The mean anterior movement, maxillary superiorinferior movement and rotation amount were 3.08 2.47 $\mathrm{mm}(\mathrm{r}=1$ to $8 \mathrm{~mm}), 0.45 \pm 2.92 \mathrm{~mm}(\mathrm{r}=-4.85$ to $5.90 \mathrm{~mm})$ and $-0.32 \pm 1.38 \mathrm{~mm}$ ( $\mathrm{r}=-3.65$ to $2.2 \mathrm{~mm}$ ) respectively (Table 1). Table 2 shows descriptive data for INV area, INV angle, ENV area, and interalar width. The mean INV area was $90.34 \pm 22.26 \mathrm{~mm}^{2}$ for the right and $89.32 \pm 25.24$ $\mathrm{mm}^{2}$ for the left before surgery. This area was increased to $104.12 \pm 31.75 \mathrm{~mm}^{2}$ for the right, and 101.18 \pm 31.31

\begin{tabular}{|l|l|}
\hline \multicolumn{2}{|l|}{ Table 1. Demographic variables of the study } \\
\hline Variable & \multicolumn{2}{l|}{32} \\
\hline Subjects & 21 \\
\hline Sex & 11 \\
\hline Female & $24.6 \pm 6.71$ \\
\hline Male & \multicolumn{2}{|l|}{} \\
\hline Mean age (year) & $3.08 \pm 2.47(r=1$ to 8$)$ \\
\hline Maxillary movement amount (mm) & $0.45 \pm 2.92(r=-4.85$ to 5.90$)$ \\
\hline Advancement & $-0.32 \pm 1.38(r=-3.65$ to 2.2$)$ \\
\hline Superior-inferior direction
\end{tabular}

$\mathrm{mm}^{2}$ for the left following the surgery. The difference between pre and postoperative values was significant for both the right and left INV area ( $1=0.005$, p2=0.007). Right INV angle was increased in twenty-five patients $(r=0.710$ to 11.20), whereas it was decreased in seven patients ( $r=-6.940$ to -0.190 to) (Figure 3). Left INV angle was increased in twenty-six patients $(r=0.210$ to 13.100), and it was decreased in five patients ( $r=-7.030$ to -1.100) (Figure 3). The mean right and left INV angle was increased from $16.15 \pm 3.240$ to $19.63 \pm 5.210$ and from $15.93 \pm 3.260$ to $19.17 \pm 4.430$ respectively. These changes were also found significant for the right and left sides (p1=0.000, p2=0.007). The correlation between the left INV area and the left internal nasal angle was significant $(p=0.000, r=0.583)$. Correlation between the right INV area and the right internal nasal angle was also significant

\begin{tabular}{|c|c|c|c|}
\hline Variable & T1 & T2 & $p^{*}$ \\
\hline $\begin{array}{l}\text { Right internal nasal valve } \\
\text { angle (0) }\end{array}$ & $16.15 \pm 3.240$ & $19.63 \pm 5.210$ & 0.000 \\
\hline $\begin{array}{l}\text { Left internal nasal valve } \\
\text { angle }(0)\end{array}$ & $15.93 \pm 3.260$ & $19.17 \pm 4.430$ & 0.007 \\
\hline $\begin{array}{l}\text { Right internal nasal valve } \\
\text { area }\left(\mathrm{mm}^{2}\right)\end{array}$ & $90.34 \pm 22.26$ & $104.12 \pm 31.75$ & 0.005 \\
\hline $\begin{array}{l}\text { Left internal nasal valve } \\
\text { area }\left(\mathrm{mm}^{2}\right)\end{array}$ & $89.32 \pm 25.24$ & $101.18 \pm 31.31$ & 0.007 \\
\hline $\begin{array}{l}\text { Total internal nasal valve } \\
\text { area }\left(\mathrm{mm}^{2}\right)\end{array}$ & $179.66 \pm 34.81$ & $205.30 \pm 45.18$ & 0.000 \\
\hline $\begin{array}{l}\text { Right external nasal } \\
\text { valve area }\left(\mathrm{mm}^{2}\right)\end{array}$ & $114.97 \pm 36.11$ & $123.52 \pm 34.04$ & 0.000 \\
\hline $\begin{array}{l}\text { Left external nasal valve } \\
\text { area }\left(\mathrm{mm}^{2}\right)\end{array}$ & $107.82 \pm 29.76$ & $115.20 \pm 30.24$ & 0.003 \\
\hline Interalar width $(\mathrm{mm})$ & $35.87 \pm 4.15$ & $39.15 \pm 3.59$ & 0.000 \\
\hline \multicolumn{4}{|c|}{$\begin{array}{l}\text { "paired samples t-test: It was used to determine whether the } \\
\text { changes in the pre and postoperative periods were significant. T1: } \\
\text { Preoperative, T2: Postoperative, SD: Standard deviation }\end{array}$} \\
\hline
\end{tabular}

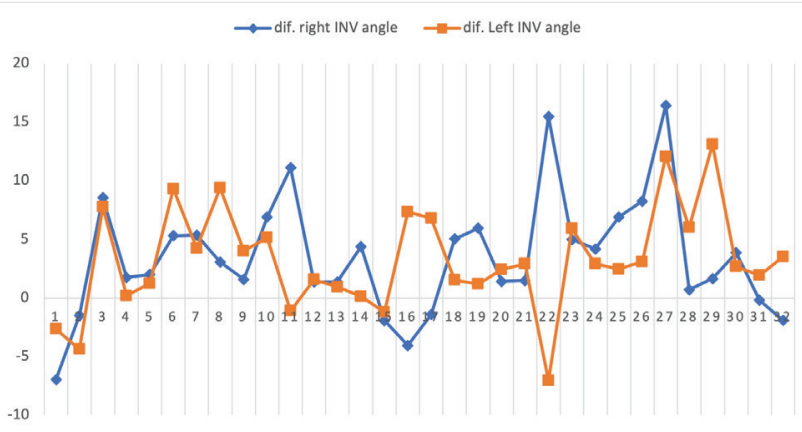

Figure 3. Difference of pre and postoperative INV angle for the right and left side. Dif. Right INV angle: right internal nasal valve angle difference; dif. left INV angle: left internal nasal valve angle difference INV: Internal nasal valve 
$(p=0.011, r=0.444)$. The total INV area was increased from $179.66 \pm 34.81 \mathrm{~mm}^{2}$ at the preoperative period to $205.30 \pm 45.18 \mathrm{~mm}^{2}$ at the postoperative period. These changes were found significant $(p=000)$.

For the external nasal valve area, the preoperative area was $114.97 \pm 36.11$ for the right side and $107.82 \pm 29.76$ for the left side. Postoperative values were $123.52 \pm 34.04$ for the right side and 115.20 \pm 30.24 for the left side. There was a significant difference between pre and postoperative values for the right and left sides ( $1=0.000, p 2=0.003)$.

Inter-alar width was increased from $35.87 \pm 4.15 \mathrm{~mm}$ preoperatively to $39.15 \pm 3.59 \mathrm{~mm}$ postoperatively, which was statistically significant $(p=0.00)$. Correlation between inter-alar width and changes in total INV area was found borderline significant $(p=0.051, r=0.814)$. Correlation between inter-alar width and maxillary impaction was found borderline significant $(p=0.058, r=0.401)$.

\section{Discussion}

Le Fort I osteotomy has been routinely performed in patients with dentofacial deformity to correct malocclusion, and it has varying degrees of effect on nasal airway form and function (14). Due to that, the maxilla can be moved in any direction by Le Fort 1 osteotomy; total maxillary impaction can increase nasal airway resistance and interalar width in certain cases, which may cause a decrease in nasal airflow $(15,16)$. A previous study has shown a higher tendency to nasal airway resistance and nasal obstruction seen in patients with maxillary constriction $(17,18)$. The results presented here prove an increase in the nasal valve area, ENV, INV angle, and interalar width following Le Fort I surgery. This study's most significant finding was a positive correlation between total INV area and interalar width. From this positive correlation, it can be commented that maxillary movements and supplementary surgical procedures such as alar cinch suture may affect INV area and angle by changing interalar width.

Many studies assessed nasal valves following Le Fort I surgery, and these studies used other methods such as AS and AR. Guenthner et al. (9) stated that nasal airway resistance following maxillary repositioning was assessed by rhinomanometry, and they found a negative correlation between impaction and airflow resistance. Erbe et al. (19) evaluated changes in nasal airway using rhinomanometry and found that the cross-sectional area at isthmus nasi increased significantly and correlated with interalar width. Haarmann et al. (20) evaluated nasal airway resistance in cases performed both rhinoplasty and orthognathic surgery and found that nasal airway resistance was decreased after combined surgery. Pourdanesh et al. (21) analyzed the effect of three different maxillary surgical movements on nasal airflow, volume, and resistance after Le Fort I osteotomy. They stated that maxillary advancement and impaction associated with nasal resistance reduction, leading to improved nasal airflow. Oliveira et al. (22) found that nasal resistance was decreased, and the minimum nasal cross-sectional area was increased significantly after maxillary expansion. Yoon et al. (23) reported that INV angle and area were increased following rapid palatal expansion in pediatric patients. They also showed that the expansion amount of the maxilla had been positively correlated with nasal obstruction scores and INV angle. Similarly, another study stated a positive correlation between maxillary expansion and INV angle in adults (24). Doruk et al. (25) also found that nasal resistance decreased significantly after maxillary expansion. However, Baraldi et al. (26) assessed thirteen patients with maxillary transversal deficiency after surgically assisted maxillary expansion, and they found that the anterior minor cross-sectional area of nasal passage was not statistically different after the operation. Data from CT findings in the present study showed that widening of interalar distance increased INV area by opening nasal valves so nasal airway resistance could be reduced.

Measurements were made on a coronal slice of $\mathrm{CT}$, which was perpendicular to the estimated acoustic axis on CT. Because it was stated in a previous study that there were strong correlations between $C T$ slice obtained perpendicular to the acoustic axis and AS findings, while there was a weak correlation between AS findings and CT image that is perpendicular to the nasal floor (13).

\section{Study Limitations}

Due to the retrospective design of the present study, it has not been investigated the relationship between physical examination of nasal airway function and INV changes. The study's strength was to examine the effect of Le Fort I osteotomy on the INV. Further prospective studies assessing the relation of physical examination of nasal airway function with INV changes following Le Fort I osteotomy could be carried out.

\section{Conclusion}

According to our findings, INV area and angle were affected to some degree by changes in interalar width, so movement direction of the maxilla or supplementary surgical procedures such as alar cinch suture, which are affecting interalar width should be kept in mind that it may change nasal airway resistance.

\section{Authorship Contributions}

Concept: E.D., M.S. Design: E.D., Data Collection or Processing: E.D., K.B.A., Analysis or Interpretation: E.D., K.B.A., M.S., Literature Search: E.D., Writing: E.D., G.A., S.U., 
Conflict of Interest: No conflict of interest was declared by the authors.

Financial Disclosure: The authors declared that this study received no financial support.

\section{References}

1. Shafik AG, Alkady HA, Tawfik GM, Mohamed AM, Rabie TM, Huy NT. Computed tomography evaluation of internal nasal valve angle and area and its correlation with NOSE scale for symptomatic improvement in rhinoplasty. Braz J Otorhinolaryngol 2020;86:343-50.

2. Hilberg O. Objective measurement of nasal airway dimensions using acoustic rhinometry: methodological and clinical aspects. Allergy 2002;57(Suppl):5-39.

3. Murthy VA, Reddy RR, Pragadeeswaran K. Internal nasal valve and its significance. Indian J Otolaryngol Head Neck Surg 2013;65:400-1.

4. Moche JA, Cohen JC, Pearlman SJ. Axial computed tomography evaluation of the internal nasal valve correlates with clinical valve narrowing and patient complaint. Int Forum Allergy Rhinol 2013;3:592-7.

5. Lee J, White WM, Constantinides M. Surgical and Nonsurgical Treatments of the Nasal Valves. Otolaryngol Clin North Am 2009;42:495-511.

6. Theodore P. Michigan Manual of Plastic Surgery. In: Brown DL, Borschel GH, Levi B, editors. Philadelphia, PA: Lippincott Williams \& Wilkins; 2014. p. 412-27.

7. Sipilä J, Suonpää J. A prospective study using rhinomanometry and patient clinical satisfaction to determine if objective measurements of nasal airway resistance can improve the quality of septoplasty. Eur Arch Otorhinolaryngol 1997;254:387-90.

8. Stewart MG, Smith TL. Objective versus subjective outcomes assessment in rhinology. Am J Rhinol 2005;19:529-35.

9. Guenthner TA, Sather AH, Kern EB. The effect of Le Fort I maxillary impaction on nasal airway resistance. Am J Orthod 1984;85:308-15.

10. Bermüller $\mathrm{C}$, Kirsche H, Rettinger G, Riechelmann H. Diagnostic accuracy of peak nasal inspiratory flow and rhinomanometry in functional rhinosurgery. Laryngoscope 2008;118:605-10.

11. Bloom JD, Sridharan S, Hagiwara M, Babb JS, White WM, Constantinides M. Reformatted computed tomography to assess the internal nasal valve and association with physical examination. Arch Facial Plast Surg 2012;14:331-5.

12. Montgomery WM, Vig PS, Staab E V, Matteson SR. Computed tomography: A three-dimensional study of the nasal airway. Am J Orthod 1979;76:363-75

13. Cakmak O, Coşkun M, Celik H, Büyüklü F, Ozlüoğlu LN. Value of acoustic rhinometry for measuring nasal valve area. Laryngoscope 2003;113:295-302.
14. Eliason MJ, Schafer J, Archer B, Capra G. The Impact on Nasal Septal Anatomy and Physiology Following Le Fort I Osteotomy for Orthognathic Surgery. J Craniofac Surg 2021;32:277-81.

15. Kim HS, Son JH, Chung JH, Kim KS, Choi J, Yang JY. Nasal airway function after Le Fort I osteotomy with maxillary impaction: A prospective study using the Nasal Obstruction Symptom Evaluation scale. Arch Plast Surg 2021;48:61-8.

16. Trevisiol L, Lanaro L, Favero V, Lonardi F, Vania M, D'Agostino A. The effect of subspinal Le Fort I osteotomy and alar cinch suture on nasal widening. J Craniomaxillofac Surg 2020;48:832-8.

17. Kim SY, Park YC, Lee KJ, et al. Assessment of changes in the nasal airway after nonsurgical miniscrew-assisted rapid maxillary expansion in young adults. Angle Orthod 2018;88:435-41.

18. Williams R, Patel V, Chen YF, et al. The Upper Airway Nasal Complex: Structural Contribution to Persistent Nasal Obstruction. Otolaryngol Head Neck Surg 2019;161:171-7.

19. Erbe M, Lehotay M, Göde U, Wigand ME, Neukam FW. Nasal airway changes after Le Fort I - Impaction and advancement: Anatomical and functional findings. Int J Oral Maxillofac Surg 2001;30:123-9.

20. Haarmann S, Budihardja AS, Wolff KD, Wangerin K. Changes in acoustic airway profiles and nasal airway resistance after Le Fort I osteotomy and functional rhino surgery: A prospective study. Int J Oral Maxillofac Surg 2009;38:321-5.

21. Pourdanesh F, Sharifi R, Mohebbi A, Jamilian A. Effects of maxillary advancement and impaction on nasal airway function. Int J Oral Maxillofac Surg 2012;41:1350-2.

22. Oliveira De Felippe NL, Da Silveira AC, Viana G, Kusnoto B, Smith B, Evans CA. Relationship between rapid maxillary expansion and nasal cavity size and airway resistance: Short and long-term effects. Am J Orthod Dentofac Orthop 2008; 134:370-82.

23. Yoon A, Abdelwahab M, Liu S, et al. Impact of rapid palatal expansion on the internal nasal valve and obstructive nasal symptoms in children. Sleep Breath 2020;25:1019-27.

24. Abdelwahab M, Yoon A, Okland T, Poomkonsarn S, Gouveia C, Liu SYC. Impact of Distraction Osteogenesis Maxillary Expansion on the Internal Nasal Valve in Obstructive Sleep Apnea. Otolaryngology Head Neck Surg 2019;161:362-7.

25. Doruk C, Sökücü O, Sezer H, Canbay El. Evaluation of nasal airway resistance during rapid maxillary expansion using acoustic rhinometry. Eur J Orthod 2004;26:397-401.

26. Baraldi CE, Pretto SM, Puricelli E. Evaluation of surgically assisted maxillary expansion using acoustic rhinometry and postero-anterior cephalometry. Int J Oral Maxillofac Surg 2007;36:305-9. 